\title{
New Measures For Other Moderns
}

\author{
Julia Gatley
}

Bill McKay, in his 1999 paper, "A Possum in the Kiwi Bush", critiqued the role played by the University of Auckland's School of Architecture in the formation and promotion of one particular story of the history and development of modern architecture in New Zealand. This story centred on Vernon Brown and the Group, at the expense of a range of other players: Robin Simpson, Tibor Donner, Henry Kulka, Brenner and Associates, Vladimir Cacala, Rigby.Mullen, Mark-Brown \& Fairhead, the firm of Newman, Smith \& Greenhough, and others. McKay pointed out, quite rightly, that because the Auckland School was New Zealand's only school of architecture until the mid-1970s, the line taught there was widely accepted by the country's practitioners and educators, until well after the establishment of a second school. He has not been the sole critic of the Groupcentred canon or its formation: Lloyd Jenkins (1998), Clark and Walker (2000), Clark (2004) and others have further elucidated the basic premise.

The purpose of this article is not to defend the School, its history or the canon, but to consider the latter with reference to one of the School's courses. In 2006 and 2007 I taught ARCHDRC 301 Measured Drawing, a third year elective that requires students to measure extant buildings and to produce a set of plans, sections and elevations based on their measurements. Many of the drawings produced by students enrolled in this course since the 1930s are accessioned in the University's Architecture Library. They form an invaluable record of many buildings for which original design drawings do not survive, as well as buildings to which changes have been made over time.

As the Docomomo New Zealand Registers Coordinator, I have a particular interest in the documentation and conservation of New Zealand's modern buildings. It seemed to me that Measured Drawing could be usefully focused on modern buildings, at a time when their heritage values are becoming increasingly recognized, locally, nationally and, indeed, internationally. The focus would ensure that the students would be experiencing and analyzing not just any old buildings, but exemplars of modern design, often with the clever planning that characterizes post-war buildings as a result of materials shortages and building size constraints. Positive roll-on effects would include a record of changes being made to the measured buildings over time and, potentially, the extension of the Library's existing collection of measured drawings through the production and acquisition of plans, sections and elevations for significant modern buildings not measured and drawn in previous years.

To achieve this, I needed a sense of what had been studied in previous years. I learnt that, to a certain extent, the Library's collection of measured drawings did accord with the thesis regarding the Auckland School's privileging of the Group. Up until 2005, the modern buildings that had been measured and drawn 


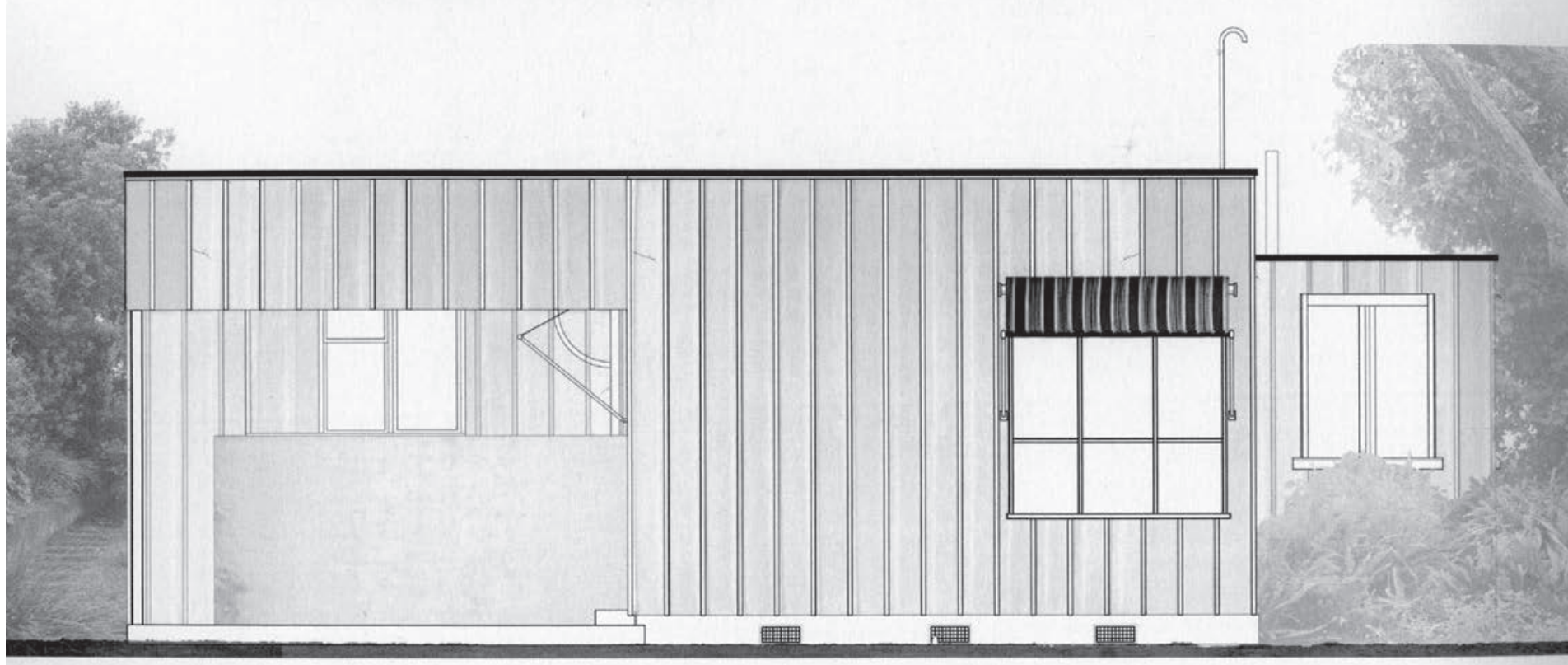

included seven houses by Group members: the Rotherham House (in 1983, 1990 and 1992); the Thompson House (in 1983); the First House (in 1984); Devonport Navy housing (in 1988); the Catley House (in 1993); the Mallitte House (in 1995); and the Worrall House (in 2002). Other architects associated with the Auckland School whose buildings have been measured and drawn include: Richard Toy's All Saints' Church, Ponsonby (in 1995); Mike Austin's Chapple House (in 1995); and David Mitchell's Music School and Gibbs House (in 1987 and 2000 respectively). Vernon Brown is a surprising absence from the collection. Other surprises, given the canon, include the presence of Tibor Donner's Ellen Melville Pioneer Women's Hall (measured and drawnin 1992 and 1995) and SavageMemorial (in 2000); Newman Smith \& Greenhough's Wanganui War Memorial Hall (in 1994); and Mark-Brown \& Fairhead's Newton Post Office (in 2000). Not enough to challenge the thesis, but just enough to complicate it. It should also be acknowledged here that more recent initiatives within the School such as Michael Milojevic and Sarah Treadwell's 2003 exhibition and catalogue, The House, and Charles Walker's 2005 exhibition and catalogue, Models for Living, have demonstrated a more inclusive approach.

My analysis of the Library's collection of measured drawings confirmed that there was plenty of scope for pursuing the measuring and drawing of modern buildings within the course. Thus, in 2006, three of the 14 buildings measured and drawn were modern: one at my suggestion, a second at a student's suggestion, and a third at another academic's request. These included the Robin Simpson House in Greenlane (1938-1939). A floor plan had been published in Home and Building in 1940, but it is believed that none of Simpson's original drawings have survived. Thus, the measurements and drawings by Daniel Bosher, Patrick Loo and James Pearce have a value above and beyond the learning objectives of a student assignment.

In 2007, I pursued modern buildings more overtly, writing to the owners of 15 such buildings (Group as well as non-Group), domestic in scale though not necessarily houses, asking if I could include their buildings in the course. I was delighted to receive eight affirmative replies. A student added a ninth building to the list. Those measured and drawn this year were: Tibor Donner's own house and studio in Titirangi (1947 and ca. 1950s respectively); the Second Group House in Takapuna (1950-1951); James Hackshaw's Thom House in Mt Albert (1953); Albert

Robin Simpson's Own House, Greenlane (1938-1939). Measured by Daniel Bosher, Patrick Loo and James Pearce; west elevation drawn by Patrick Loo (2006). 
Robin Simpson's Own House, Greenlane (1938-1939). Measured by Daniel Bosher, Patrick Loo and James Pearce; section drawn by Daniel Bosher (2006). and/or John Goldwater's Jewish Centennial Memorial Chapel in Karangahape Road (1953); Rigby.Mullen's Rayner House in Remuera (1954); Vladimir Cacala's Kay House in Remuera (1960); Lillian and David Chrystall's Yock House in Remuera (1964); and Marshall Cook's Howard House in Meadowbank (1969).

It is my pleasure to be able to publish a selection of the drawings here. Three students worked on each building, together producing a set of plans, sections and elevations and a range of details. I stipulated A1 sized paper, but did not impose traditional drawing techniques on the students. Rather, I allowed them the freedom to pursue the creative presentation that they enjoy in the design studio, including hand or computer drawing and the use of pen or pencil, monochrome or colour. For record purposes, I encouraged the inclusion of the main dimensions on the drawings and analytical annotations regarding design, materiality, additions, alterations and current condition.

There will always be varying degrees of accuracy in the measurements and a range of finesse in the drawings, but the work being produced in the course is already making a useful contribution to the Library's records of these individual places. I believe it has been a valuable learning experience for students to date, and I hope it will encourage further research in the future on modern architecture in New Zealand.

\section{References}

Clark, J. (2004). Ephemera: The Elusive Canon of New Zealand Architecture. Fabrications: The Journal of the Society of Architectural Historians, Australia and New Zealand 14 (1/2), 4757.

Clark, J., and Walker, P. (2000). Looking for the Local: Architecture and the New Zealand Modern. Wellington: Victoria University Press.

Lloyd Jenkins, D. (1998). Rebuilding Robin Simpson. In J. Willis, P. Goad and A. Hutson (Eds.). FIRM(ness) commodity DE-light?: Questioning the Canons; Papers from the Fifteenth Annual Conference of the Society of Architectural Historians, Australia and New Zealand. (pp. 183-188). Melbourne: SAHANZ.

McKay, B. (1999). A Possum in the Kiwi Bush. In R. Blythe and R. Spence (Eds.). Thresholds: Papers of the Sixteenth Annual Conference of the Society of Architectural Historians, Australia and New Zealand (pp. 209-212). Launceston, Tas: SAHANZ. 
Measured Drawing Collection, Architecture Library, The University of Auckland.

Milojevic, M., and Treadwell, S. (2003). The House: Architecture Archive. Auckland: School of Architecture, University of Auckland.

Simpson, W. R. (1940). An Architect Designs His Own House. Home and Building 4 (4), 5-7.

Walker, C. (2005). Models for Living, 1905-2005: A Survey of 100 Years of New Zealand Residential Architecture. Auckland: AGM Publishing.
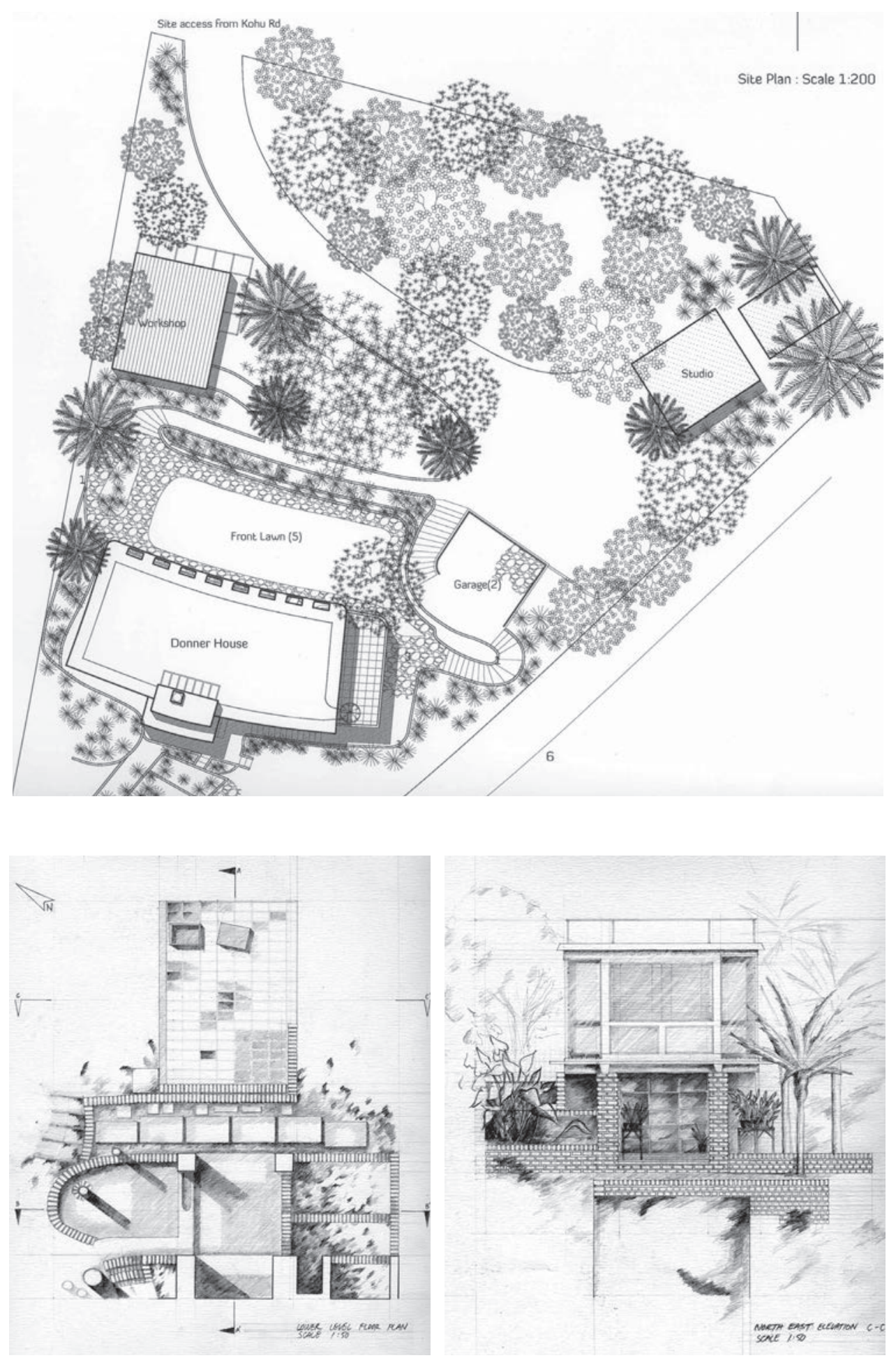

Tibor Donner's Own House, Titirangi (1947). Measured by Deborah Graham, Kuhu Gupta, Nickolas Morris; drawn by Kuhu Gupta (2007).

Tibor Donner's Own Studio, Titirangi (1950s). Measured by Pio Faalogo, Adam Morrow and Kirsten Smedley; drawn by Adam Morrow (2007). 
Rigby.Mullen, Rayner House, Remuera (1954). Measured by Victor Eng, Tim Yun Yunny Luk and Derek Yichi Zhang; drawn by Victor Eng (2007).

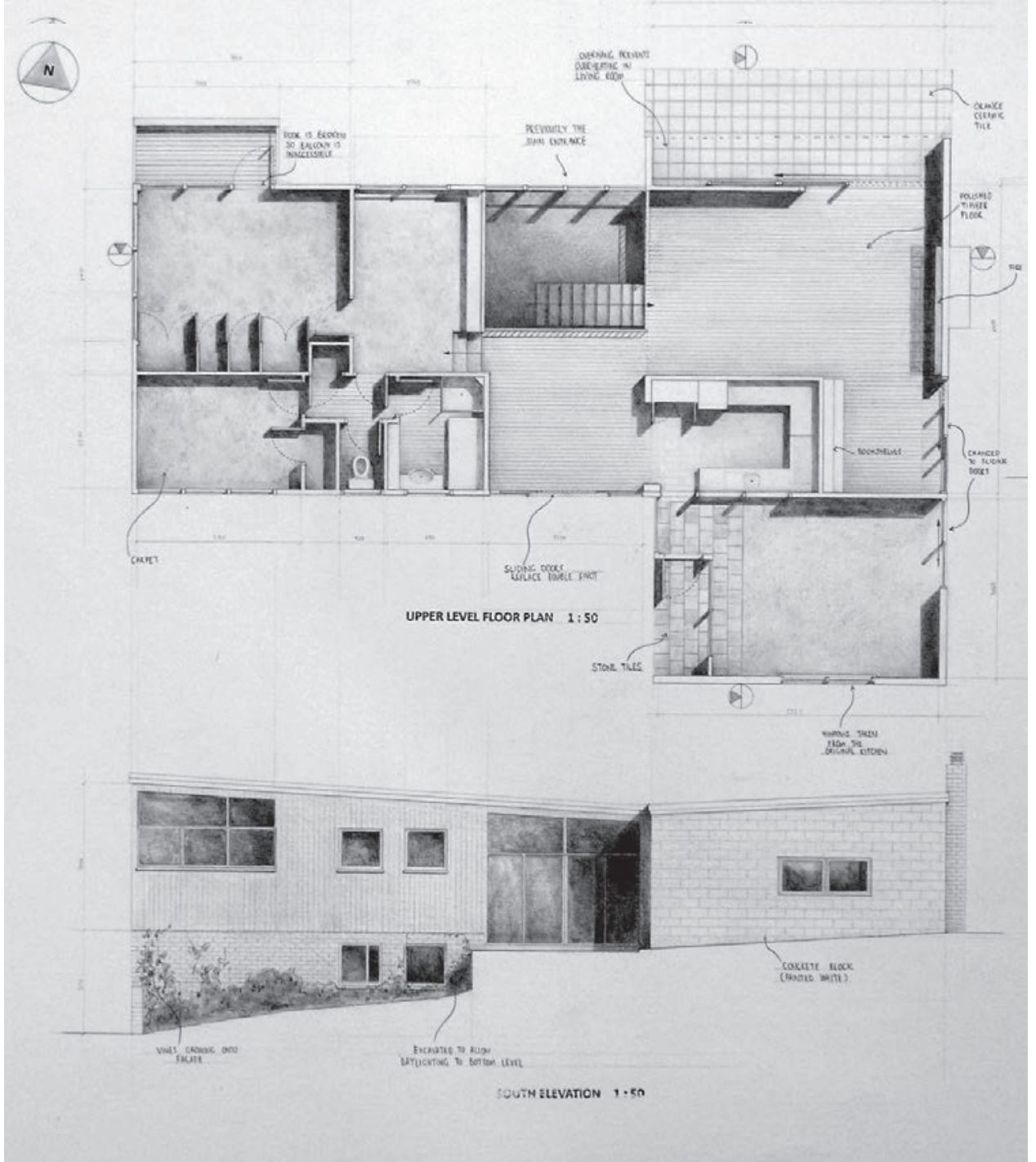

Lillian and David Chrystall, Yock House, Remuera (1964). Measured by Felicity Brouwers, Adelle Hammond and Julian Legg; drawn by Felicity Brouwers.

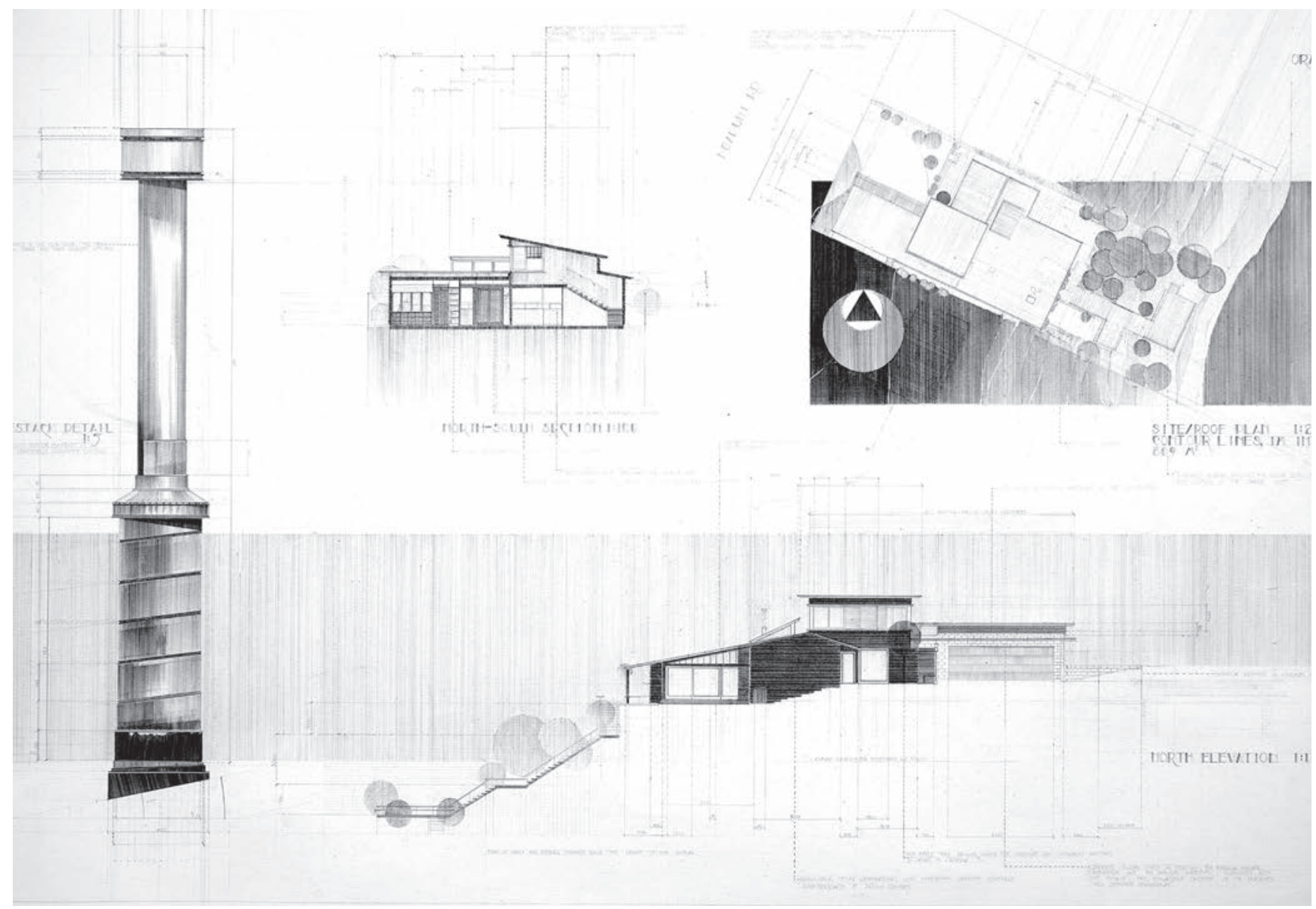



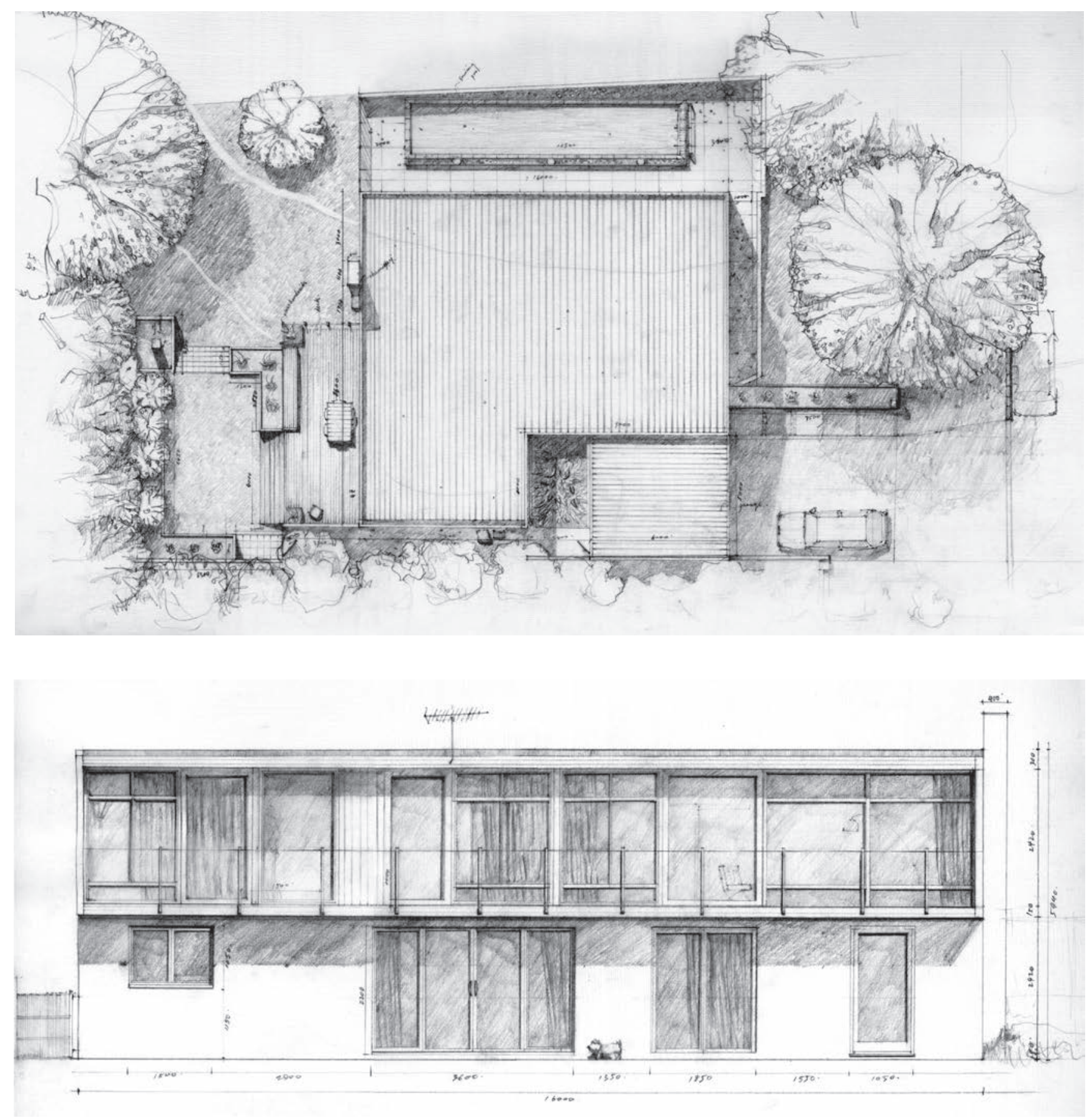

Vladimir Cacala, Kay House,

Remuera (1960). Measured by Kit

Kwan Leung, Dajiang Tai and

Junpei Zhao; drawn by Dajiang Tai. 